\title{
DIFFERENCES IN RELATIVE PROSPECTIVE AGE DETERMINED BY COHORT AND PERIOD LIFE TABLES
}

\author{
TOMÁŠ FIALA ${ }^{\mathrm{a},{ }^{*},}$ JITKA LANGHAMROVÁa \\ fiala@vse.cz, langhamj@vse.cz \\ ${ }^{a}$ University of Economics in Prague, Faculty of Informatics and Statistics, Department of Demography, \\ W. Churchill Sq. 4, Prague, Czech Republic
}

\begin{abstract}
Increasing the pension age above the usual threshold of 65 years is very often recommended to ensure financial sustainability of old-age pension systems, especially of those based on the PAYG principle. At the same time, a closer and clearer relation between the pension age threshold and the level of mortality is required. A possible way may be using the concept of so-called "relative" prospective age, which would ensure that the average proportion of the time of receiving an old-age pension to the total life span would remain approximately constant. It seems to be natural to determine the relative prospective age using not period, but cohort life tables. But cohort life tables are not as widely available as period ones. Moreover, it is proven that in some cases cohort and period prospective ages are almost identical. The paper presents a comparison of differences in retirement ages based on the relative prospective age concept derived by cohort life tables and by period ones separately for Czechia, Slovakia, Poland and Spain. Computations are based on the latest available Eurostat data and population projection.
\end{abstract}

\section{Key words}

prospective age, relative prospective age, period life tables, cohort life tables

\section{JEL classification}

J11, H55, J26

\section{Introduction}

Demographic ageing is one of the most important phenomena of the present century (e.g. Gavrilov and Heuveline, 2003). The main reasons for it are not only permanent increase in life span but also decrease of fertility of females, in many countries below the replacement level. In some countries or regions the third not so often mentioned cause of ageing is a massive emigration of young adult people in reproductive age.

Population ageing is very often regarded as a serious threat to the financial sustainability of welfare systems (mainly of the pension and health care systems). The reason is expected increase of population of retirees and decrease of productive population. But almost all such concerns are based on the assumption of fixed threshold between productive and postproductive age (usually equal to 65 years of age).

Already in 1975 Ryder has published the idea of re-examination of the concept of fixed threshold of old age. "We measure age in terms of the number of years elapsed since birth. This seems to be a useful and meaningful index of the stages of development from birth to maturity. Beyond maturity, however, such an index becomes progressively less useful as a clue to other important characteristics. To the extent that our concern with age is what it signifies about the degree of deterioration and dependence, it would seem sensible to consider the measurement of age not in terms of years elapsed since birth but rather in terms of the number of years remaining until death." (Ryder, 1975, p. 16.) He suggested the idea to considere the point of entry into old age as the value of age at which the life expectancy is equal to a given, relatively low, value, say, e.g. 10 years. 
In the 1970's this Ryder's idea was mentioned relatively rarely because the population ageing has not been considered to be a serious threat yet. The idea of flexible old age depending on the life expectancy was suggested also by Fuchs (1984). Siegel (1993) proposed the idea of the old-age threshold defined as the age when the life expectancy equals to 15 years.

The idea of new concept of human's age and new indicators based of forward-looking conception was treated by Sanderson and Scherbov in several papers. They introduced a new forward-looking definition of age and argued that, along with the traditional backward-looking concept of age, this definition provides a more informative basis to discuss population aging (Sanderson and Scherbov, 2005). Their concept of so called prospective age was defined as the age in which the remaining life expectancy is the same as the remaining life expectancy of a person in given reference (standard) year (Sanderson and Scherbov, 2007). The indicators of ageing based on prospective age instead of biological age show that the increase of many indicators of ageing in such a case will not be so dramatically in comparison with indicators defined by standard way (Sanderson and Scherbov, 2010, 2013). Computations of some indicators of this type for Czech population are presented e.g. by Klapková et al. (2016).

\section{Prospective age and relative prospective age}

The concept of prospective age is based on the assumption that for adult people living under different mortality patterns (i.e. living in different periods or in different types of populations) it can be more important not their age defined by usual way (i. e. lengths of the time interval they already lived) but average lengths of their remaining life characterized by their remaining life expectancy. The attribute remaining is recommended to use by Sanderson and Scherbov to emphasize the difference between the life expectancy at births usually used and the life expectancy at higher ages. "Using chronological age, we are lead implicitly to think that people of the same age in different years would behave similarly, but because of life expectancy increases there are aspects of behavior where this might not be the case. For example, a 45 year old in 2050 might well behave in many ways like a 35 year old in 2000 if they had the same remaining life expectancy. It is precisely because many behaviors depend on the number of years left to live that it is important to supplement the usual backward-looking definition of age with a forward-looking one" (Sanderson and Scherbov, 2007, p. 28.).

Let us denote by $e_{x}^{(t)}$ the remaining life expectancy at the age $x$ in the year $t$. Choosing some reference mortality pattern, the prospective age $y(x, t)$ of a person of (retrospective) age $x$ in the year $t$ means the age for which the remaining life expectancy in the year $t$ is the same as the remaining life expectancy $e_{x}^{*}$ at the age $x$ in the reference mortality pattern. The prospective age should thus fulfill the equation

$$
e_{y(x, t)}^{(t)}=e_{x}^{*}
$$

It is clear that under the assumption of mortality decrease in time the prospective age defined by (1) should be higher than chronological age for years higher then reference year and vice versa. In the example mentioned above if we choose reference mortality pattern as of the expected mortality in 2000 , then the prospective age of a 35 year old age person in 2050 would be 45 years.

Usually there exist no integer value $y(x, t)$ fulfilling (1). Let us find the (unique) integer value of age $y_{0}(x, t)$ for which $e_{y_{0}(x, t)}^{(t)} \geq e_{x}^{*}$, while $e_{y_{0}(x, t)+1}^{(t)}<e_{x}^{*}$. The prospective age would subsequently be found by the linear interpolation formula

$$
y(x, t)=y_{0}(x, t)+\frac{e_{y_{0}(x, t)}^{(t)}-e_{x}^{*}}{e_{y_{0}(x, t)}^{(t)}-e_{y_{0}(x, t)+1}^{(t)}} .
$$


The concept of biological ages characterizes the lengths of years lived, the prospective age takes into account the expected lengths of remaining life. More informative to analyze aging and its economic and social consequences would be combining both a backward-looking and a forward-looking age measure. Possible indicator of such a type could be relative remaining life expectancy defined as a proportion of the remaining life expectancy of the expected total life span

$$
r e_{x}^{(t)}=\frac{e_{x}^{(t)}}{x+e_{x}^{(t)}}
$$

This indicator characterizes the length of remaining life not absolutely (the expected number of years left) but relatively (the expected proportion of life left).

Relative prospected age can be than defined by an analogous way to prospective age (2). The relative prospective age $r y(x, t)$ of a person of (retrospective) age $x$ in the year $t$ is defined as the value for which the relative remaining life expectancy in the year $t$ is the same as the relative remaining life expectancy $r e_{x}^{*}$ at the age $x$ of the reference mortality pattern

$$
r y(x, t)=r y_{0}(x, t)+\frac{r e_{y_{0}(x, t)}^{(t)}-r e_{x}^{*}}{r e_{y_{0}(x, t)}^{(t)}-r e_{y_{0}(x, t)+1}^{(t)}},
$$

where $y_{0}(x, t)$ is the integer value of age for which $r e_{y_{0}(x, t)}^{(t)} \geq r e_{x}^{*}$, while $r e_{y_{0}(x, t)+1}^{(t)}<r e_{x}^{*}$ (Fiala and Langhamrová, 2018).

For measuring the expected number of years of remaining life it would be natural and more correct to use cohort life expectancy. Nevertheless cohort life tables are not as widely available as period ones because their construction is based not only on latest available data on mortality but also on some prediction of future mortality development. Sanderson and Scherbov (2007, Chapter 3 and 4) proved that in some cases the cohort and period prospective ages are almost identical or with minor differences only. Their study concerns historical examples of population aging from Sweden and England and Wales. Of course almost identical value of prospective age or relative prospective age does not mean identity of values of the absolute or relative remaining life expectancy which is in cohort tables usually a little bit higher in comparison with period tables.

The goal of this paper is to compare values of relative prospective age for old-age persons in Czechia, Poland, Slovakia and Spain (separately for males and females) computed by both (period and cohort) types of life tables. The first three states are the countries of the main conference participants, Spain has been selected for comparison because its life expectancy is the highest in the Europe.

\section{Methodological remarks}

Computations of life tables is usually based on mortality rates by age and sex. Their values for selected countries since 1960 until 2014 came from Eurostat database of life tables ${ }^{1}$ (age units until 85+ years), since 2015 until 2080 the mortality scenario of baseline variant of population projection (age units until 100 years) has been used $^{2}$. Probabilities of dying were computed by standard formula

$$
q_{t, x}=1-e^{-m_{t, x}},
$$

where $m_{t, x}$ denotes mortality rate in the age $x$ in the year $t$, for ages $x=0,1, \ldots, 84$ since 1960 until 2014 and for ages $\mathrm{x}=0,1, \ldots, 100$ since 2015 until 2080 .

\footnotetext{
${ }^{1}$ Eurostat Database: http://appsso.eurostat.ec.europa.eu/nui/show.do?dataset=demo_mlifetable\&lang=en

${ }^{2}$ Eurostat Projection: http://appsso.eurostat.ec.europa.eu/nui/show.do?dataset=proj_15naasmr\&lang=en
} 
Probabilities of dying for higher age until 110 years were estimated by the model of geometric (exponential) interpolation

$$
q_{t, x}=k_{t}^{x-x_{0}} \cdot q_{t, x_{0}}
$$

where $x_{0}=84$ in the period 1960-2014, $x_{0}=100$ in the period 2015-2080, and the coefficient of increase $k_{t}$ in the year $t$ is defined so that $q_{t, 110}=1$

$$
k_{t}=\sqrt[110-x_{0}]{\frac{1}{q_{t, x_{0}}}}
$$

Probabilities of dying for years 2081-2131 were estimated also by the model of geometric (exponential) trend after 2080 for each age $x$

$$
q_{t, x}=r_{x}^{t-2080} \cdot q_{2080, x}
$$

where $r_{x}$ is average relative coefficient of mortality decrease in the age $x$ in the last projection decade

$$
r_{x}=\sqrt[10]{\frac{q_{2080, x}}{q_{2070, x}} .}
$$

These probabilities of dying are prospective. Cohort probabilities can be estimated using the fact that a person born in the year $g$ will spent the complete age $x$ partly in the year $x+g$ and partly in the following year $x+g+1$. Probability of dying at the age $\mathrm{x}$ of a person born in the year $\mathrm{g}$ can be estimated by the average value of corresponding period probabilities

$$
q_{x}^{(g)}=\frac{q_{g+x, x}+q_{g+x+1, x}}{2} .
$$

Having values of period probabilities of dying since 1960 until 2130 we can compute values of cohort probabilities for all ages of cohorts born in 1960-2020. For older cohorts it is possible to compute probabilities of dying only for higher ages since the age 1960-g. For Poland we have data only since 1990, for Spain since 1975, so some values for these countries are missing.

Computation of life expectancies is going on using standard known formulas for life table computations.

\section{Values of relative life expectancies for selected ages in Czechia, Slovakia, Poland and Spain}

The values of relative life expectancies for Czechia, Slovakia, Poland and Spain for ages near to retirement age $(55,60,65$ and 70 years) are shown in Figure 1. Spain has been chosen because the life expectancy in this country is one of the highest in Europe. Cohort values are values for cohorts, which reach the given age in given year. (E.g. cohort value in the year 1960 for the age 55 is the value for cohort born in 1905). In standard case with permanent declining mortality cohort values are should be a little bit higher then period values because they reflect the future decrease of mortality. This is the case of Spain. But in Czechia and Slovakia cohort values in the 1960's and 1970's are not too much different from period ones, in the case of males in some years cohort values are even lower than period ones. The reason is that there was a stagnation and in some period even increase of male's mortality in Czechoslovakia in that period. Only after 1980 and mainly after 1990 there begun decrease of mortality in Czechia. Nevertheless Czech life expectancy is still lower than in Spain and it is expected to be so also in the future although the differences should gradually diminish. 
Figure 1: Relative remaining life expectancy for selected ages (period and cohort values) (in \%)
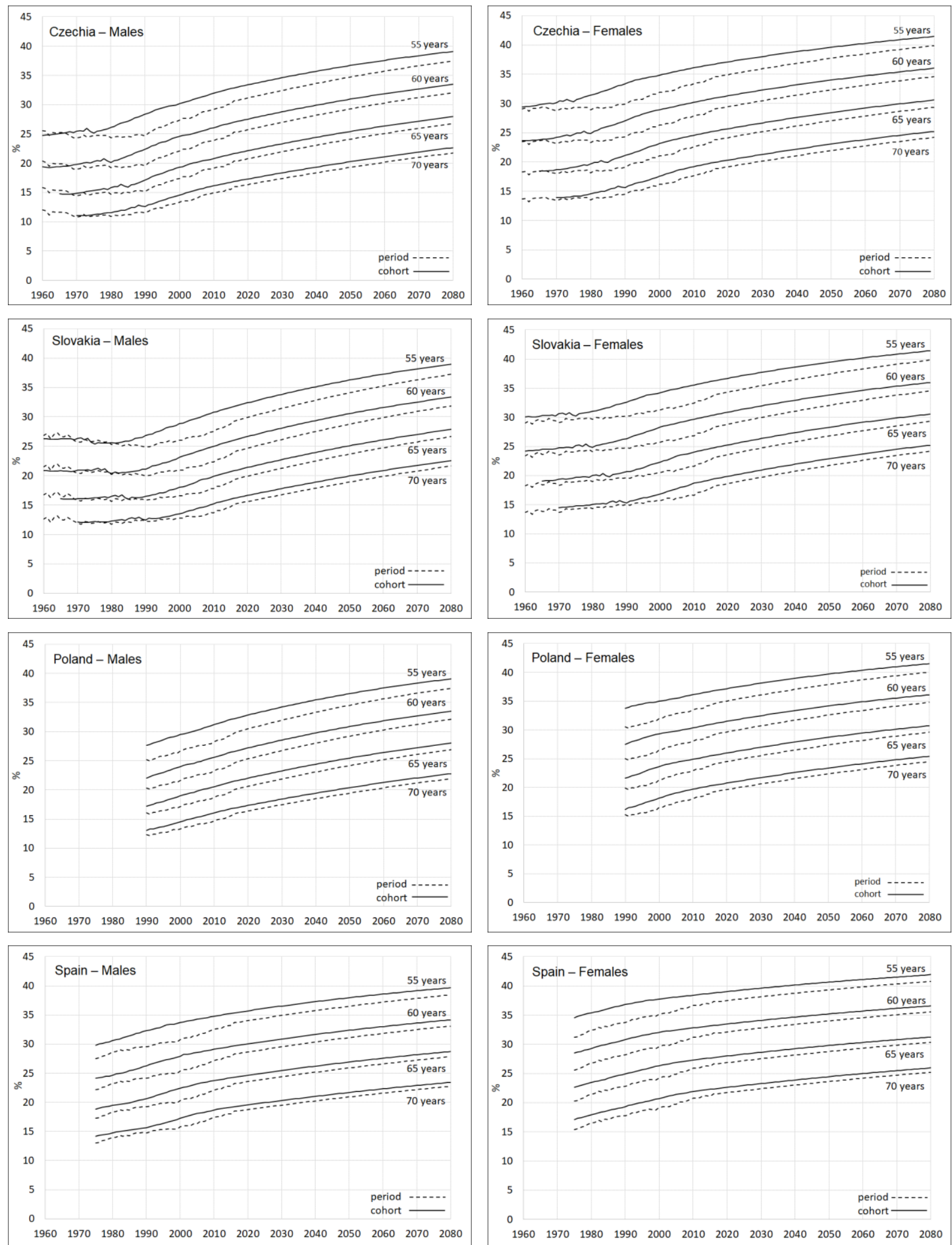

Source: the authors based on data from Eurostat.

\section{Relative prospective age for Czechia, Slovakia, Poland and Spain}

The concept or relative prospective age shall be used e.g. for determination of the retirement age in Czechia after 2030. The idea is that the retirement age should be determined in such 
a way that average proportion of pension receipt with respect to the total life span of people who will survive until senior age should not change too much in time. In Czechia the recommended proportion is a quarter of the total life span.

According to present legislation in Czechia the retirement age depends on the year of births and is gradually growing. It should reach the level 65 years for the persons born in 1965, they would thus retire in 2030. For the following computations of relative prospective age for period table computations the reference year 2030 has been chosen, for cohort computations the reference cohort will be 1965 . The reference (chronological) age is 65 years in both cases.

The period relative prospective for each year shows the age at which the period relative remaining life expectancy for given year reaches the same value as the relative life expectancy at the age 65 years in 2030. The cohort value in the year $t$ shows the age $x$ at which the cohort born in the year $t-x$ has the same relative remaining life expectancy like the cohort born in 1965 at the age 65 years.

The relation between period and cohort values of prospective age is ambiguous and uneven. At the beginning of the period observed the cohort values in Czechia and Slovakia are lower than period ones. The main reason is the stagnation of mortality in that countries, especially for males. Data for Spain and Poland for this period are not available. On the other hand after 1980 the situation is changed and cohort values are usually higher then period ones. This can be caused by acceleration of decrease of mortality and so increase of life expectancy. In some years the differences are higher than 2 years, see Figure 2.

In 2030 the values of both period and cohort relative prospective age are of course equal to 65 years. Later on there are lower differences between period and cohort values because the mortality scenario of the Eurostat projection assumes continuing decrease of death probabilities without fluctuations. The differences are lower than half of a year.

Figure 2: Relative prospective age - period and cohort values
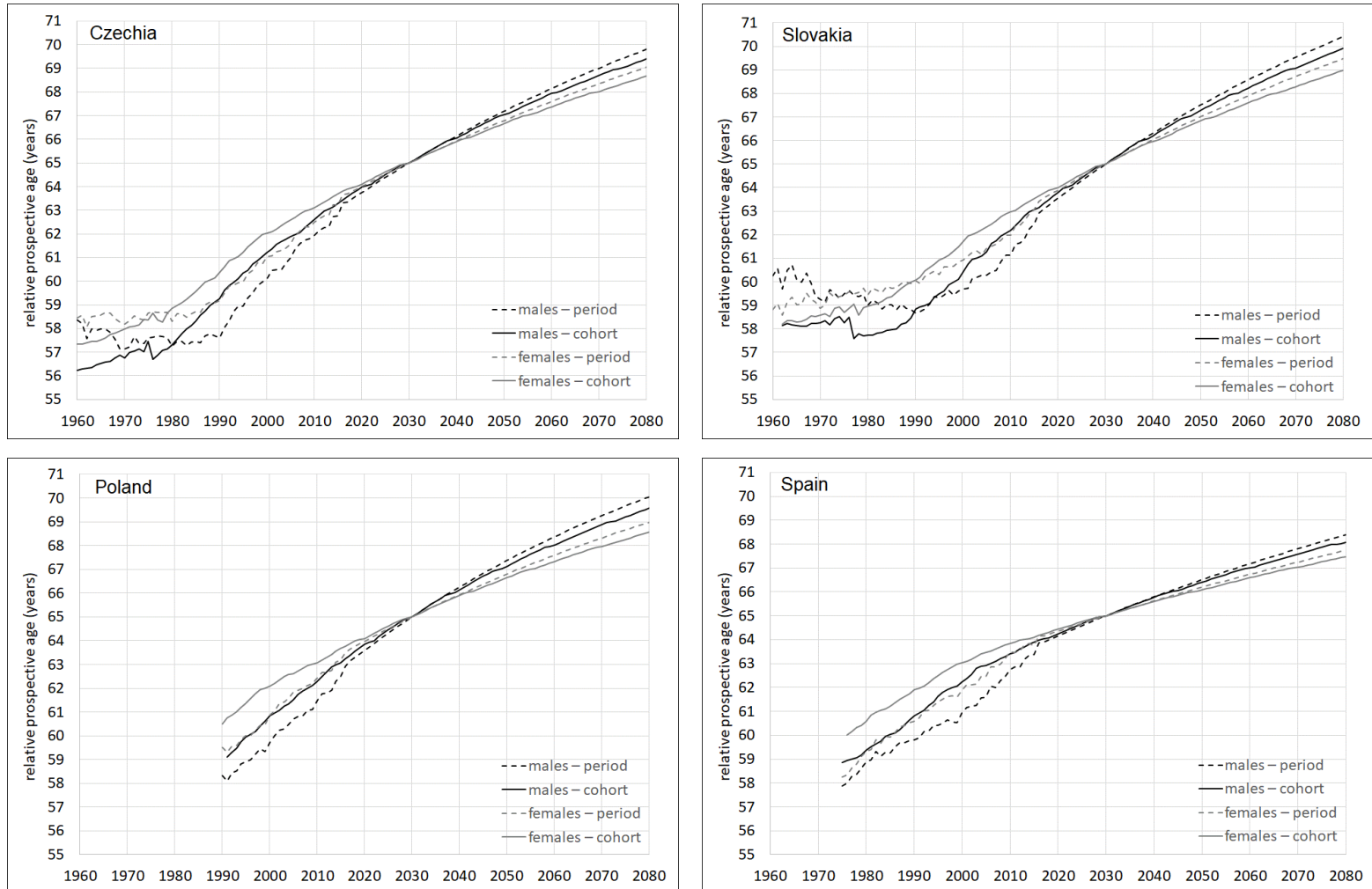

Source: the authors based on data from Eurostat. 


\section{Conclusion}

The main goal of the paper is comparison of values of relative prospective age computed by period and cohort method. In the case of Czechia and Slovakia there are in the 1960 and 1970 lower cohort values and relatively high differences due to stagnation of mortality development (and in the case of males even due to increase of mortality in some age groups). On the other hand, since 1980 there are higher cohort values caused by rapid acceleration of mortality decrease. In the projected period the differences between period and cohort values are much lower.

For determination of retirement age in such a way that the relative period of pension receipt would be approximately the same in all countries and all pension cohorts computations of relative prospective age based on cohort life tables should be used, because exactly cohort life tables describe the life span of real population and take into account the expected future changes in mortality of the population investigated. But because of low differences between values of relative prospective age based on period and cohort life tables it seems that for Czechia, Poland, Slovakia and Spain (and probably for other European countries having similar development of mortality) values based on period tables can serve as preliminary estimates of relative prospective age. In the future it would be interesting to do such computations for longer time series of data or for other European and maybe for some non-European countries.

\section{Acknowledgements}

The paper was supported by the grant scheme GAČR No. 19-03984S "Economy of successful ageing".

\section{References}

[1] Fiala, T., Langhamrová, J. 2018. Pension age based on relative prospective age concept. In Applications of Mathematics and Statistics in Economics, AMSE 2018. Prague: Oeconomica, 2018. 9 pp. ISBN 978-80-245-2277-7.

[2] Fuchs, V. R. 1984. Though much is taken: Reflections on aging, health, and medical care. In Health and Society, 1984, vol. 62, iss. 2, pp. 142-166.

[3] Gavrilov, L. A., Heuveline, P. 2003. Aging of population. In Demeny, P., McNicoll, G. (eds.). The encyclopedia of population. New York : Macmillan, 2003.

[4] Klapková, M., Šídlo, L., Šprocha, B. 2016. Koncept prospektivního věku a jeho aplikace na vybrané ukazatele demografického stárnutí. In Demografie, 2016, vol. 58, pp. 126-141.

[5] Ryder, N. B. 1975. Notes on stationary populations. In Population Index, 1975, vol. 41, iss. 1, pp. 3-28.

[6] Sanderson, W. C., Scherbov, S. 2005. Average remaining lifetimes can increase as human populations age. In Nature, 2005, vol. 435, iss. 7043, pp. 811-813.

[7] Sanderson, W. C., Scherbov, S. 2007. A new perspective on population aging. In Demographic Research, 2007, vol. 16, pp. 27-58.

[8] Sanderson, W. C., Scherbov, S. 2010. Remeasuring aging. In Science, 2010, vol. 329, iss. 5997, pp. 1287-1288.

[9] Sanderson, W. C., Scherbov, S. 2013. The characteristics approach to the measurement of population aging. In Population and Development Review, 2013, vol. 39, iss. 4, pp. 673-685.

[10] Siegel, J. S. 1993. A Generation of change: A profile of America's older population. New York : Russell Sage Foundation, 1993. 